\title{
Estratégias de Diversificação em Áreas de Cultivo de Tabaco no Vale do Rio Pardo: uma análise comparativa ${ }^{1}$
}

\author{
Marco Antonio Vargas² e Bruno Ferreira de Oliveira ${ }^{3}$
}

\begin{abstract}
Resumo: Este trabalho apresenta um panorama dos aspectos socioeconômicos do cultivo do tabaco no Brasil e analisa a viabilidade de outras culturas agrícolas em relação à produção de fumo a partir de evidências empíricas oriundas de uma pesquisa de campo que envolveu uma amostra de 299 produtores rurais na região do Vale do Rio Pardo, no Rio Grande do Sul. Os resultados encontrados demonstram que a renda líquida advinda de culturas alternativas ao fumo, como hortifrutigranjeiros, pode ser superior à obtida por fumicultores. Tais evidências contradizem as análises comparativas envolvendo fumo e demais culturas agrícolas geralmente veiculadas pela indústria fumageira. Adicionalmente, o estudo destaca que qualquer iniciativa específica de diversificação da cultura do fumo deve estar inserida em programas amplos de desenvolvimento rural, particularmente nas regiões/municípios que têm alta dependência em relação ao fumo como a região em questão.
\end{abstract}

Palavras-chaves: cultura do fumo, estratégias de diversificação, desenvolvimento rural.

Abstract: This paper presents the main results of the socio-economic assessment of small farmers involved with tobacco crops and other cash crops in the Vale do Rio Pardo region, in Rio Grande do Sul state, in Brazil. The study aims to provide evidences for the implementation of effective crop substitution and diversification programs in tobacco producing countries/regions. A questionnaire survey involved a sample of 299 small family farms in the Vale do Rio Pardo region. The sample was designed to include both small

$1 \mathrm{O}$ artigo se baseia em pesquisa financiada pelo International Development Research Centre (IDRC) no Canadá, através do programa Research for International Tobacco Control (RITC). Essa instituição não tem qualquer responsabilidade sobre as opiniões e conclusões do trabalho. Os autores agradecem também a valiosa colaboração de Carmem Menezes, Paula Camboim e Renato Michel, do Núcleo de Pesquisas Sociais da Universidade de Santa Cruz do Sul (Nupes-Unisc), no tratamento estatísticos dos dados; e aos comentários e sugestões recebidos de dois pareceristas anônimos da revista.

2 Professor do Departamento de Economia da UFF. E-mail: mvargas@economia.uff.br

3 Mestrando do Programa de pós-graduação em Economia da UFF. E-mail: brunooliver17@hotmail.com 
farmers who are fully or partially dedicated to tobacco production and farmers who are mainly dedicated to other agricultural products instead of tobacco. The study shows that, in the Vale do Rio Pardo region, tobacco farming activities account for about $60 \%$ of the gross value of the production in agriculture. However, the comparative analysis of the profitability of tobacco crops and other cash crops in this region shows that alternative crops might offer lower gross income than tobacco, but offer a higher net income, because their production costs are lower.

Key-words: tobacco crops, crop substitution strategies, rural development.

Classificação JEL: L11, Q01, R11.

\section{Introdução}

Há evidências substanciais que apontam para os efeitos nocivos do controle exercido pela indústria do fumo sobre a organização da cadeia agroindustrial do tabaco nos países em desenvolvimento. O sistema de produção utilizado pelos agricultores que cultivam tabaco demanda mão de obra intensiva e exige uma quantidade considerável de pesticidas e outros agroquímicos. Os problemas mais conhecidos em relação a este sistema de produção incluem riscos à saúde e danos ao meio ambiente, resultantes do uso inapropriado de pesticidas e do desmatamento, o emprego de mão de obra infantil associado ao uso extensivo de trabalho familiar no cultivo do tabaco e o endividamento de pequenos agricultores junto às grandes empresas fumageiras. ${ }^{4}$

Entretanto, a adoção de estratégias de diversificação e as medidas de controle voltadas à redução da produção do tabaco ainda enfrentam barreiras consideráveis. A falta de recursos para investimentos, a ausência de canais de comercialização para grande parte das culturas agrícolas tradicionais e outras restrições, tais como limitações na infraestrutura de transporte e armazenamento, são fatores que contribuem para dificultar a transição da cultura do fumo

4 Para uma análise detalhada das principais preocupações relativas à saúde e à segurança de pequenos agricultores que cultivam fumo no Sul do Brasil, ver estudo da Christian Aid/Deser disponível em: http://www.christian-aid.org.uk/indepth/0201bat/ para cultivos alternativos. Da mesma forma, a adoção de políticas governamentais de controle voltadas à substituição da cultura do fumo por culturas alternativas ainda enfrenta restrições nos principais países produtores, dado o receio quanto aos potenciais efeitos prejudiciais que tais medidas possam provocar em termos de perdas de postos de trabalho na agricultura e diminuição das receitas de impostos e de exportações. ${ }^{5}$ Em qualquer contexto, verifica-se um amplo espaço para adoção de políticas públicas que busquem tanto a intensificação da pesquisa sobre alternativas viáveis ao cultivo do tabaco quanto a criação e implementação de programas de desenvolvimento rural voltados à assistência da transição de produtores de tabaco para outros empreendimentos.

O Brasil representa hoje o segundo maior mercado produtor de fumo em folha e mantém, há alguns anos, sua posição de maior exportador de fumo no mercado mundial. Apesar de as exportações de fumo em folha não apresentarem uma participação expressiva na balança comercial brasileira, a cultura do fumo apresenta grande relevância na produção agrícola e na renda

5 Cabe ressaltar que existe um conjunto crescente de evidências científicas que demonstram que os receios em relação a efeitos nocivos que as políticas de controle do tabaco poderiam exercer sobre a economia dos países produtores de fumo revelam-se amplamente infundados quando dados e evidências da real economia do tabaco e do controle do tabaco são analisados. Para uma análise abrangente sobre a importância econômica do tabaco, ver, entre outros, Jacobs et al. (2000), Van der Merwe (1998), Warner et al. (1995) e Buck et al. (1995). 
gerada em determinadas localidades do País, particularmente na região Sul, que responde por mais de $90 \%$ da produção nacional de fumo. Neste aspecto, destaca-se em particular a região do Vale do Rio Pardo que, além de representar o mais importante elo da indústria do fumo no País, conta com diversos municípios cuja economia depende substancialmente de atividades associadas à cultura do fumo. Ainda que essa região apresente algumas iniciativas importantes voltadas à substituição do fumo por outras culturas agrícolas, o peso econômico da cultura do fumo na economia local e a ausência de estudos que apontem para a viabilidade econômica de culturas alternativas são fatores que limitam o alcance de tais iniciativas de diversificação.

O principal objetivo deste estudo é analisar a viabilidade de outras culturas agrícolas à produção de fumo no Brasil, a partir de dados que foram coletados em uma pesquisa de campo envolvendo uma amostra de 299 produtores rurais situados em diferentes municípios na região do Vale do Rio Pardo no estado do Rio Grande do $\mathrm{Sul}^{6}$. Tal análise parte de um panorama geral sobre os aspectos socioeconômicos da cultura do fumo no mundo e no Sul do Brasil e busca relacionar a importância relativa da cultura do fumo nos municípios da região do Vale do Rio Pardo com outros indicadores associados aos níveis de renda e desenvolvimento humano. A seguir, o estudo apresenta os principais resultados da pesquisa de campo no tocante à caracterização econômica e estruturas de receitas e custos de produtores ligados majoritariamente à cultura do fumo e de produtores rurais dedicados a outras atividades agrícolas na região.

6 O projeto de pesquisa intitulado "The impact of tobacco farming on local development and rural livelihoods in Brazil: socioeconomic assessment of diversification strategies in the Rio Pardo Valley region" contou com apoio financeiro do International Development Research Centre (IDRC), no Canadá. A realização da pesquisa de campo contou com o apoio técnico do Núcleo de Pesquisas Sociais da Universidade de Santa Cruz do Sul.

\section{Fundamentação teórica}

Em termos conceituais, este artigo fundamenta-se em torno de dois eixos centrais de análise que apresentam elevada relevância no estudo das estratégias de diversificação da cultura do fumo na região do Vale do Rio Pardo. $\mathrm{O}$ primeiro refere-se ao conceito de meios de vida sustentáveis (sustaineable livelihoods) e seu impacto na criação e implementação de políticas de desenvolvimento local. O segundo eixo, que é complementar ao primeiro, remete ao debate sobre o papel central da agricultura familiar no contexto atual de desenvolvimento rural no Brasil.

Conforme destacado por Scoones (1998), a origem da abordagem de meios de vida esteve, em grande parte, associada ao trabalho de Chambers (1983), que focalizava a necessidade de melhoria das condições de vida de populações rurais nos países em desenvolvimento. ${ }^{7} \mathrm{O}$ conceito de "meios de vida" proposto por autores como Chambers e Conway (1992) pode ser definido como "as capacidades, atividades e recursos (tanto materiais quanto sociais) necessários para o sustento. Um meio de vida é sustentável quando pode enfrentar e recuperar-se de um estresse ou impacto, mantendo ou expandindo sua capacidade e seus bens, tanto no presente, quanto no futuro, sem prejuízo para os recursos naturais que lhe servem de base" (DFDI, 1999, p. 1).

Ao longo da década de 90, a partir das contribuições de autores como Chambers e Conway (1992), Scoones (1998) e Carney (1998), o modelo analítico decorrente da abordagem sobre meios de vida sustentáveis foi amplamente adotado por diversas instituições em âmbito mundial no processo de avaliação sobre os objetivos e alcance de políticas de desenvolvimento. ${ }^{8}$

7 Chambers, R (1983) Rural Development: putting last First. London, Longman.

8 Cabe destacar o papel pioneiro do Ministério para o Desenvolvimento Internacional do governo britânico (DFID) na consolidação desse arcabouço analítico através da elaboração, em 1997, de um 
A abordagem sobre meios de vida oferece, portanto, um conjunto de lentes importantes para discussão de questões relativas ao desenvolvimento rural a partir de um arcabouço analítico que busca obter uma compreensão realista dos aspectos que moldam os meios de vida das pessoas e da forma como os diferentes fatores que os influenciam podem ser ajustados para que, juntos, produzam os melhores resultados. Entretanto, conforme enfatizado por autores como Scoones (2009), entre as limitações da abordagem dos meios de vida, destaca-se uma relativa carência de elementos que permitam articular a análise sobre os condicionantes locais do processo de desenvolvimento rural com outros fatores sistêmicos associados, por exemplo, à articulação do local com instâncias supralocais ou globais; ou mesmo com determinantes de ordem político-institucional. Nesse aspecto, cabe ressaltar que o estudo sobre os condicionantes das estratégias de diversificação da cultura do fumo na região do Vale do Rio Pardo demanda tanto a compreensão sobre as formas de articulação entre o oligopólio global do tabaco e a extensa rede de produtores integrados localmente, como também a análise sobre o papel e importância dos fatores político-institucionais na dinâmica local de produção. Considera-se, por outro lado, que essas dimensões de análise estão, em grande medida, presentes no atual debate sobre agricultura familiar no Brasil, que apresenta, portanto, complementaridades com a abordagem sobre meios de vida.

Desde a década de 90, observa-se o resgate do debate sobre o papel da agricultura familiar enquanto vetor de desenvolvimento rural e territorial que, para alguns autores, revela um esforço de dar novo significado ao conceito de pequeno produtor, que foi amplamente adotado ao longo das décadas de 60 e 70 . Tal esforço busca recolocar o conceito de agricultura familiar como elemento central na discussão sobre um novo modelo de desenvolvimento. Entretanto,

livro branco de diretrizes para Desenvolvimento Internacional. conforme é destacado por diversos autores (SCHNEIDER, 1999; VEIGA et al. 2001), é possível apontar importantes divergências em relação ao modelo proposto para agricultura familiar e que acaba por estabelecer antagonismos entre modelos que enfatizam uma agricultura familiar fortemente pautada pela lógica de mercado e pelos processos de inovação tecnológica, ${ }^{9}$ e aqueles modelos que enfatizam a autonomia relativa do pequeno produtor, bem como a importância desse modo de produção no uso sustentável de recursos locais e a diversificação da produção (OLALDE e PORTUGAL, 2005).

Não obstante a importância dos aspectos tecnológicos e de mercado observa-se a importância crescente atribuída ao papel da agricultura familiar no âmbito de processos mais amplos e sistêmicos de desenvolvimento local e regional. Tal perspectiva logra superar as limitações decorrentes de uma visão de caráter mais "produtivista" que restringe a função das atividades agrícolas ao campo do fornecimento de alimentos, matérias-primas e divisas. Da mesma forma, aumenta a complexidade da análise do tema ao estabelecer a noção de multifuncionalidade da agricultura e resgatar a dimensão territorial da atividade rural, em contraposição ao caráter setorial historicamente atribuído ao termo (FROEHLICH et al., 2005).

Assim, em linhas gerais, a noção de multifuncionalidade da agricultura referese ao reconhecimento de que a agricultura e os agricultores possuem uma contribuição que extrapola a mera produção agropecuária, podendo propiciar também a garantia de qualidade dos alimentos, o desenvolvimento de sistemas agrícolas diversificados, a manutenção do tecido econômico e social rural, bem como a conservação, preservação e sustentabilidade ambiental no meio rural. (LAURENT, 2000 apud FROEHLICH et al., 2005).

\footnotetext{
9 Nesse sentido ver, por exemplo, Buainain M. et al. (2007). Agricultura Familiar e Inovação Tecnológica no Brasil: característica, desafios e obstáculos. Campinas, Editoria da Unicamp, 2007.
} 
Tabela 1. Estratificação da amostra segundo os municípios pesquisados.

\begin{tabular}{|c|c|c|c|c|c|c|}
\hline \multirow{3}{*}{ Município } & \multicolumn{6}{|c|}{ Identificação do grupo } \\
\hline & \multicolumn{2}{|c|}{ Fumicultor } & \multicolumn{2}{|c|}{ Não fumicultor } & \multicolumn{2}{|c|}{ Total } \\
\hline & $\mathbf{n}$ & $\%$ & $\mathbf{n}$ & $\%$ & $\mathbf{n}$ & $\%$ \\
\hline Venâncio Aires & 46 & 20,7 & 14 & 18,2 & 60 & 20,1 \\
\hline Candelária & 51 & 23,0 & 7 & 9,1 & 58 & 19,4 \\
\hline Santa Cruz do Sul & 20 & 9,0 & 36 & 46,8 & 56 & 18,7 \\
\hline Vale do Sol & 27 & 12,2 & 4 & 5,2 & 31 & 10,4 \\
\hline Rio Pardo & 16 & 7,2 & 9 & 11,7 & 25 & 8,4 \\
\hline Arroio do Tigre & 21 & 9,5 & 3 & 3,9 & 24 & 8,0 \\
\hline Passa Sete & 16 & 7,2 & 0 & 0 & 16 & 5,4 \\
\hline Passo do Sobrado & 14 & 6,3 & 2 & 2,6 & 16 & 5,4 \\
\hline Sobradinho & 11 & 5,0 & 2 & 2,6 & 13 & 4,3 \\
\hline Total & 222 & 100,0 & 77 & 100,0 & 299 & 100,0 \\
\hline
\end{tabular}

Fonte: Pesquisa de campo.

A análise sobre o conjunto de questões suscitadas a partir da abordagem sobre meios de vida sustentáveis e, particularmente, sua aplicação no contexto atual de desenvolvimento da agricultura familiar no Sul do Brasil, permeiam a discussão dos resultados do estudo sobre diversificação em áreas de cultivo de tabaco no Vale do Rio Pardo, apresentados a seguir.

\section{Metodologia}

No tocante aos aspectos metodológicos, foram pesquisados, no total, 222 produtores de fumo e 77 não fumicultores, (produtores rurais que têm sua principal atividade econômica vinculada a outras culturas que não o fumo) nos seguintes municípios da região do Vale do Rio Pardo: Venâncio Aires, Candelária, Santa Cruz do Sul, Vale do Sol, Rio Pardo, Arroio do Tigre, Passa Sete, Passo do Sobrado e Sobradinho, conforme demonstra a Tabela $1 .{ }^{10} \mathrm{~A}$ amostra dos fumicultores foi selecionada através de um sorteio aleatório entre

10 Especificamente, a margem de erro da amostra é de $6,5 \%$, e o nível de confiança, de $95 \%$. Isso quer dizer que os percentuais encontrados podem variar na população total de fumicultores e não fumicultores, os nomes de produtores associados e cadastrados na Afubra (Associação dos Fumicultores do Brasil), obedecendo-se a proporcionalidade do total de produtores por município da região do Vale do Rio Pardo. A amostra dos não fumicultores foi selecionada aleatoriamente nos municípios onde foram pesquisados os fumicultores, tendo em vista características semelhantes em termos de tamanho de propriedade e escala de produção. Essa estratificação foi crucial para permitir a comparação entre as condições econômicas da cultura do fumo em relação a culturas alternativas nesta região.

O questionário utilizado para os fumicultores e não fumicultores se constituiu num formulário com questões para preencher os dados quantitativos de produção e outras questões fechadas com opções preestabelecidas para as respostas. Especificamente, o questionário foi construído com quatro áreas temáticas: i) dados da propriedade e forma de ocupação do estabelecimento; ii) atividade agropecuária anual; iii) custos de produção da principal cultura agrícola e iv) dados da família. A pesquisa de campo foi realizada entre março e abril de 2009.

referida anteriormente, das mencionadas regiões, 6,5 pontos percentuais, para mais ou para menos. 


\section{A cultura fumageira no Brasil: evolução e perspectivas}

Esta seção está dividida em duas partes. A primeira apresenta um breve panorama da indústria brasileira do fumo e destaca o crescente papel desempenhado pelo Brasil e por outros países em desenvolvimento nas exportações mundiais de tabaco. A segunda parte discute a inserção da região do Vale do Rio Pardo no contexto da produção nacional de fumo a partir de indicadores de produção, comercialização e exportação de fumo no Sul do Brasil e nos municípios da região.

\subsection{A cultura do fumo no Brasil no contexto da indústria mundial do tabaco}

As atividades de cultivo do fumo estão dispersas em mais de 100 países em todo o mundo, sendo os países em desenvolvimento responsáveis por cerca de $85 \%$ da produção mundial. Os principais países produtores de fumo estão apresentados na Tabela 2, abaixo. A República Popular da China é o maior produtor mundial de fumo e responde por $38 \%$ do total da produção mundial. No entanto, como a China consome a maior parte de sua produção, o país ainda não representa uma ameaça significativa a outros países produtores no mercado internacional. Os Estados Unidos foram o segundo maior produtor até 1998, mas sua participação caiu de 10,2\% em 1998 para 5,6\% em 2007.

O Brasil tornou-se recentemente o segundo maior produtor mundial e consolidou sua posição como o maior exportador mundial de fumo. Este crescimento da produção e exportação do fumo brasileiro pode ser diretamente atribuído a um conjunto de fatores, em que se destacam: (i) os custos de produção comparativamente baixos; (ii) o sistema de produção integrada, envolvendo contratos firmados diretamente entre agricultores e indústrias e (iii) a qualidade do fumo Virgínia produzido no Brasil (VARGAS, 2005, p. 2).

A expansão da presença do fumo brasileiro no mercado internacional reflete, também, uma tendência importante de transferência do cultivo do fumo para os países de rendas média e baixa ao longo das duas últimas décadas (BANCO

Tabela 2. Principais países produtores de fumo e área cultivada de fumo em folha, 2007.

\begin{tabular}{lcccc}
\hline & $\begin{array}{c}\text { Produção (toneladas) } \\
\mathbf{( 2 0 0 7 )}\end{array}$ & $\begin{array}{c}\text { Participação no volu- } \\
\text { me total mundial }\end{array}$ & $\begin{array}{c}\text { Área cultivada (ha) } \\
\mathbf{( 2 0 0 7 )}\end{array}$ & $\begin{array}{c}\text { Participação na área } \\
\text { total mundial }\end{array}$ \\
\hline China & 2.397 .200 & $37,89 \%$ & 1.401 .200 & $35,68 \%$ \\
Brasil & $\mathbf{9 1 9 . 3 9 3}$ & $\mathbf{1 4 , 5 3 \%}$ & $\mathbf{4 6 1 . 4 8 2}$ & $\mathbf{1 1 , 7 5 \%}$ \\
Índia & 555.000 & $8,77 \%$ & 380.000 & $9,68 \%$ \\
Estados Unidos da América & 353.177 & $5,58 \%$ & 144.068 & $3,67 \%$ \\
Indonésia & 180.000 & $2,85 \%$ & 215.000 & $5,47 \%$ \\
Turquia & 98.000 & $1,55 \%$ & 146.000 & $3,72 \%$ \\
Grécia & 18.500 & $0,29 \%$ & 17.400 & $0,44 \%$ \\
Argentina & 170.000 & $2,69 \%$ & 92.000 & $2,34 \%$ \\
Itália & 100.000 & $1,58 \%$ & 35.000 & $0,89 \%$ \\
Paquistão & 126.000 & $1,99 \%$ & 62.000 & $1,58 \%$ \\
Tailândia & 70.000 & $1,11 \%$ & 40.000 & $1,02 \%$ \\
Malaui & 118.000 & $1,87 \%$ & 155.000 & $3,95 \%$ \\
Coreia do Sul & 63.000 & $1,00 \%$ & 45.000 & $1,15 \%$ \\
Zimbábue & 79.000 & $1,25 \%$ & 51.800. & $1,32 \%$ \\
Resto do mundo & 1.078 .982 & $17,06 \%$ & 681.618 & $17,35 \%$ \\
Mundo & $\mathbf{6 . 3 2 6 . 2 5 2}$ & $\mathbf{1 0 0 , 0 0 \%}$ & 3927568 & $\mathbf{1 0 0 , 0 0 \%}$ \\
\hline
\end{tabular}

Fonte: Faostat. Disponível em: http://faostat.fao.org; Unctad (2009). 
Tabela 3. Áreas cultivadas com fumo no Brasil em 2007.

\begin{tabular}{lccccc}
\hline \multirow{2}{*}{ Brasil/regiões } & \multicolumn{2}{c}{ Área cultivada } & \multicolumn{2}{c}{ Quantidade produzida } & \multicolumn{2}{c}{$\begin{array}{c}\text { Valor da produção } \\
\text { (Mil reais) }\end{array}$} \\
\cline { 2 - 4 } & Hectares & $\%$ & Toneladas & $\%$ & 3.583 .963 \\
Brasil & 460.343 & 100,00 & 908.679 & 100,00 & 3.509 .765 \\
Região Sul & 431.715 & 93,78 & 880.327 & 96,88 & 71.663 \\
Região Nordeste & 27.691 & 6,02 & 27.526 & 3,03 & 1.183 \\
Região Norte & 475 & 0,10 & 514 & 0,06 & 1.176 \\
Região Sudeste & 262 & 0,06 & 152 & 0,02 & 176 \\
Região Centro-Oeste & 200 & 0,04 & 160 & 0,02 & \\
\hline
\end{tabular}

Fonte: IBGE - Produção Agrícola Municipal (PAM), (2007).

MUNDIAL, 1999). Os países em desenvolvimento ampliaram sua participação na produção mundial de fumo de $51 \%$ para $85 \%$ entre 1962 e 2005; a participação total da produção de fumo pelos países desenvolvidos caiu de 49\% para $14,8 \%$ no mesmo período (FAO, 2003).

A participação crescente dos países em desenvolvimento na produção mundial de fumo é explicada por diversos fatores. Em primeiro lugar, os custos de produção nos países em desenvolvimento são mais baixos que nos países desenvolvidos. Segundo, o hábito de fumar vem declinando nos países desenvolvidos, enquanto a demanda por tabaco nos países em desenvolvimento - tanto para produção de cigarros quanto para exportações - tem aumentado, catalisando a crescente produção de fumo. Em terceiro lugar, como parte de uma tendência global mais ampla durante a década de 90, as empresas multinacionais do tabaco estabeleceram presença crescente nos países em desenvolvimento e estimularam a expansão do cultivo do fumo para abastecer as novas plantas industriais. Finalmente, em muitos países em desenvolvimento, o fumo ainda é considerado uma plantação relativamente rentável, especialmente se comparada com outras culturas tradicionais de alimentos (BANCO MUNDIAL, 1999, p. 61). Além disto, existem benefícios indiretos associados ao cultivo do fumo, que incluem empréstimos, insumos, apoio técnico ou outras formas de apoio, sejam elas por parte dos governos ou das indústrias, e sistemas de comercialização bem desenvolvidos que ajudam a transformar o fumo numa cultura atrativa para os pequenos agricultores nos países em desenvolvimento e que colocam obstáculos aos esforços de transição do fumo para culturas alternativas (JACOBS et al., 2000; BANCO MUNDIAL, 1999, p. 5; VARGAS e CAMPOS, 2005).

\subsection{Cultivo do fumo no Brasil e no Vale do Rio Pardo: produção e mercados}

Em 2007, segundo dados do IBGE (PAM - Produção Agrícola Municipal), a produção brasileira de fumo foi de 908 mil toneladas, equivalente a $\mathrm{R} \$ 3,5$ bilhões, em uma área de 460 mil hectares. A região Sul é responsável por 93,8\% da produção brasileira, sendo que o Rio Grande do Sul responde, sozinho, por mais da metade da produção total.

De acordo com os dados do IBGE, a cultura do fumo está presente em 763 municípios ou $65 \%$ dos municípios da região Sul. Se forem considerados somente os municípios em que produção de fumo tem alguma significância (produção superior a 20 toneladas), chega-se a 645 municípios (144 no Paraná, 223 em Santa Catarina e 278 no Rio Grande do Sul).

No Rio Grande do Sul, a produção de fumo concentra-se principalmente nas mesorregiões Centro Oriental(200 mil toneladas), Metropolitana de Porto Alegre (67 mil toneladas), Sudeste (60 mil toneladas) e Noroeste (56 mil toneladas). Destacam-se, na região Sul, os municípios de Venâncio Aires, Candelária, Canguçu, Santa 
Cruz do Sul, Camaquã e São Lourenço do Sul. Em Santa Catarina, a mesorregião do Vale do Itajaí é a principal produtora (80 mil toneladas), seguida pelo Sul (73 mil toneladas), Norte (62 mil toneladas) e Oeste Catarinense (50 mil toneladas). Em termos municipais, os que se destacam são: Canoinhas, Itaiópolis, Santa Terezinha, Araranguá e Ireneópolis. No Paraná, a produção está mais concentrada nas regiões Centro-Sul (83 mil toneladas), Sudoeste e Metropolitana de Curitiba (ambas com 24 mil toneladas). Os principais municípios produtores são os de Rio Azul, Ipiranga, Piên e São João do Triunfo. Na região Nordeste do País, a produção de fumo apresenta maior importância relativa nos estados da Bahia, Sergipe e Alagoas.

A região do Vale do Rio Pardo representa um importante elo na indústria fumageira do Brasil, representando cerca de $20 \%$ da produção nacional de fumo, segundo dados do IBGE (2007), sustentando uma extensa rede que conecta pequenos agricultores a empresas fumageiras transnacionais e aos mercados globais. A maioria dos 25 municípios que integram essa região é substancialmente dependente das atividades associadas à cultura do fumo e à indústria fumageira. Ainda que esta dependência econômica tenha criado barreiras consideráveis à substituição do fumo por culturas alternativas, a região também apresenta iniciativas importantes voltadas ao aprimoramento da produção agroecológica.

A forte dependência da cultura do fumo nos municípios da região do Vale do Rio Pardo pode ser analisada pelo peso da produção do fumo na composição do Valor Agregado da agricultura regional. Em 2007, a cultura do fumo respondia por $66,4 \%$ do Valor Bruto da Produção da agricultura na região. Neste mesmo período, a participação elevada do fumo no valor da produção agrícola regional mostrava-se mais crítica em municípios como Herveiras (90,33\%), Gramado Xavier $(87,21 \%)$, Sininbu $(80,06 \%)$ e Vera Cruz $(79,50 \%)$.

Como em grande parte destes municípios o Valor Adicionado Bruto do setor agropecuário possui relevância significativa na riqueza local, intui-se que, de forma relativa, a cultura fumageira constitui-se como uma fonte importante para a geração de riqueza local, expressa por meio do PIB Municipal.

Embusca de se relacionar a importância relativa da cultura do fumo nos municípios da região com os níveis de renda e de desenvolvimento humano associado aos indicadores de PIB per capita e

Tabela 4. Participação relativa do fumo no Valor Bruto da Produção Agrícola Municipal, Produto Interno Bruto Municipal per capita e IDH nos municípios do Vale do Rio Pardo.

\begin{tabular}{lccccc}
\hline \multicolumn{1}{c}{ Municípios } & $\begin{array}{c}\text { Participação \% do } \\
\text { fumo no VBP da } \\
\text { agricultura (2007) }\end{array}$ & $\begin{array}{c}\text { Participação \% VBP } \\
\text { agricultura município } \\
\text { na região (2007) }\end{array}$ & $\begin{array}{c}\text { Produção de fumo em } \\
\text { folha (em toneladas) } \\
\text { (2007) }\end{array}$ & $\begin{array}{c}\text { IDH -M } \\
\text { (2000) }\end{array}$ & $\begin{array}{c}\text { PIB per } \\
\text { capita em } \\
\text { R\$ (2006) }\end{array}$ \\
\hline Arroio do Tigre & 74,04 & 6,98 & 15.275 & 0,764 & 12425 \\
Barros Cassal & 77,10 & 3,08 & 8.000 & 0,695 & 8148 \\
Candelária & 62,16 & 11,12 & 24.200 & 0,756 & 9039 \\
Gramado Xavier & 87,21 & 1,98 & 5.500 & 0,749 & 9457 \\
Herveiras & 90,33 & 1,35 & 3.960 & 0,76 & 8955 \\
Santa Cruz do Sul & 75,05 & 7,67 & 16.300 & 0,817 & 23435 \\
Segredo & 78,04 & 3,42 & 7.900 & 0,72 & 8507 \\
Sinimbu & 80,06 & 3,85 & 8.930 & 0,768 & 10404 \\
Sobradinho & 76,69 & 1,86 & 4.536 & 0,753 & 9084 \\
Venâncio Aires & 75,92 & 12,26 & 10.920 & 0,793 & 16377 \\
Vera Cruz & 79,50 & 4,64 & 201.088 & 0,791 & 14838 \\
Vale do Rio Pardo & 66,36 & - & 0,751 & 14573 \\
\hline
\end{tabular}

Fonte: Elaboração própria, a partir dos dados do IBGE (2009). 
IDH (Índice de Desenvolvimento Humano) ${ }^{11}$, na Tabela 4, são expostos alguns indicadores para tal análise.

Conforme pode ser observado na tabela, em nenhum dos municípios da região a participação relativa do fumo no total do valor da produção agrícola municipal é inferior a $60 \%$. Entre os municípios da região que apresentam maior participação na composição do total do Valor Bruto da Produção na agricultura na região do Vale do Rio Pardo destacam-se Venâncio Aires $(12,26 \%)$, Candelária $(11,12 \%)$, Santa Cruz do Sul $(7,67 \%)$ e Arroio do Tigre (6,98\%). Em termos do volume de produção de fumo em folha, estes municípios produziram conjuntamente $65,41 \%$ do total do fumo em folha da região em 2007.

A análise do Produto Interno Bruto (PIB) per capita, para a região e para os municípios, mostra que, em 2006, a região do Vale do Rio Pardo apresentava um PIB per capita de R\$ 14.573, superior ao PIB per capita estadual (equivalente a R\$ 13.310 no mesmo período). Entretanto, verifica-se também uma elevada variação no valor do PIB per capita entre os diferentes municípios da região. Neste aspecto, destaca-se uma elevada assimetria entre os valores de PIB per capita municipal, entre os municípios da região, a exemplo da diferença existente entre o PIB per capita de Barros Cassal (R\$ 8.148) e o de Santa Cruz do Sul (R\$23.435). Tal contraste é explicado, em parte, pelo maior dinamismo do setor industrial nos municípios de Santa Cruz, Venâncio Aires e Vera Cruz em contraposição aos demais cuja base econômica ainda reside nas atividades agrícolas.

Adicionalmente, verifica-se que a maior parte dos municípios desta região apresenta um IDH-M

11 De forma qualitativa, o IDH é uma sinalização da evolução do desenvolvimento socioeconômico de uma determinada localidade. Assim, ao mesmo tempo em que a região do Vale do Rio Pardo apresenta uma elevada participação do fumo no total da produção agrícola do estado, também apresenta índices de desenvolvimento socioeconômico inferiores, em média, aos dos demais municípios do estado do Rio Grande do Sul. inferior ao IDH médio do estado do Rio Grande do Sul $(0,814)$. Em particular, verifica-se que os IDH-M mais baixos da região são encontrados nos municípios de Barros Cassal $(0,695)$, Segredo $(0,720)$, Gramado Xavier $(0,749)$ e Sobradinho $(0,751)$, onde a participação do fumo no VBP da agricultura é, em média, superior a $80 \%$.

Isto posto, a próxima seção irá abordar os principais resultados obtidos pela pesquisa de campo feita na região do Vale do Rio Pardo com os produtores rurais, fumicultores ou não, justamente para poder extrair informações importantes para auxiliar na formulação e proposição de alternativas para a cultura fumageira na região.

\section{Resultados: caracterização socioeconômica de fumicultores e não fumicultores na região do Vale do Rio Pardo}

Uma das questões importantes na caracterização socioeconômica dos produtores rurais na região é a estrutura fundiária e o tamanho do estabelecimento. De acordo com os resultados da pesquisa, enquanto o tamanho médio das propriedades entre as famílias que não produzem fumo é de 13,6 hectares, entre os produtores de fumo esta média é de 9,8 hectares, conforme a Tabela 5. Além disso, 28,4\% dos fumicultores trabalham exclusivamente em terras arrendadas de outros, e $21,6 \%$, além de trabalharem em sua própria área de terra, arrendam área de outros, totalizando cerca de metade dos fumicultores. As limitações de área agrícola constituem um importante fator que impede os pequenos proprietários rurais fumicultores de avançarem para outras culturas, diversificando suas atividades.

No caso dos não fumicultores, do total de 77 produtores pesquisados que responderam a essa questão, $77,9 \%$ são proprietários, 1,3\% é arrendatário e 19,5\% são proprietários e arrendatários. Nesse aspecto, verifica-se uma diferença significativa no tocante à condição de propriedade entre os dois grupos de produtores 
Tabela 5. Distribuição da área do estabelecimento.

\begin{tabular}{lcccccc}
\hline & \multicolumn{2}{c}{ Fumicultor } & \multicolumn{2}{c}{ Não fumicultor } & \multicolumn{2}{c}{ Total } \\
\cline { 2 - 7 } & $\mathbf{n}$ & Média & $\mathbf{n}$ & Média & n & Média \\
\hline Área total da propriedade (ha) & 221 & 9,80 & 77 & 13,64 & 298 & 10,79 \\
terras próprias (da propriedade) (ha) & 221 & 6,98 & 77 & 12,16 & 298 & 8,32 \\
terras arrendadas de terceiros (ha) & 218 & 2,77 & 77 & 1,50 & 295 & 2,44 \\
terras arrendadas para terceiros (ha) & 222 & 0,17 & 77 & 0,42 & 299 & 0,23 \\
Outras (parceria etc.) (ha) & 222 & 0,01 & 77 & 0,01 & 299 & 0,01 \\
\hline
\end{tabular}

Fonte: Pesquisa de campo.

pesquisados, na medida em que os produtores cuja principal atividade não é o fumo produzem, majoritariamente, em terras próprias.

No tocante à infraestrutura das propriedades, $99,5 \%$ das propriedades de fumicultores pesquisadas entre os 222 que responderam essa questão possuem energia elétrica e apenas 0,5\% não possui. No caso de não fumicultores, $100 \%$ das propriedades possuem energia elétrica.

Entre os fumicultores, o tempo médio de permanência na cultura do fumo é de 24,7 anos. Do total de 222 fumicultores que responderam a essa questão, cerca de $43 \%$ afirmaram produzir fumo há 20 anos ou menos, sendo que cerca de $25 \%$ dos entrevistados dedicam-se à cultura do fumo há pelo menos 30 anos. Este elevado tempo médio de permanência dos entrevistados neste tipo de cultura reflete uma tradição histórica da cultura do fumo na região do Vale do Rio Pardo, que teve origem com a vinda dos primeiros imigrantes alemães para a região ainda no século XIX.

Um dos principais objetivos do presente estudo reside precisamente na análise comparativa entre as atividades desenvolvidas por fumicultores e não fumicultores na região do Vale do Rio Pardo, tendo em vista, em particular, as diferenças existentes em termos de suas estruturas de receitas e custos. Nesse aspecto, apresenta-se a seguir uma análise preliminar dos resultados da pesquisa no tocante a essas questões.

De acordo com as informações obtidas junto aos produtores sobre a área destinada aos diversos tipos de culturas agrícolas, verifica-se que a cultura do fumo ocupa, em média, 3,7 ha da área total

Tabela 6. Distribuição da área da propriedade destinada à produção agrícola.

\begin{tabular}{lcccc}
\hline \multicolumn{1}{c}{$\begin{array}{c}\text { Área - culturas agrícolas } \\
\text { (ha) }\end{array}$} & Média & $\begin{array}{c}\text { Participação \% na área } \\
\text { total da propriedade }\end{array}$ & Média & $\begin{array}{c}\text { Participação \% na área } \\
\text { total da propriedade }\end{array}$ \\
\cline { 2 - 5 } & 0,05 & 0,51 & 0,31 & 2,27 \\
Arroz & 0,02 & 0,20 & 0,14 & 1,03 \\
Batatinha & 0,02 & 0,20 & 0,10 & 0,73 \\
Cebola & 0,00 & 0,00 & 0,23 & 1,69 \\
Erva-Mate & 0,20 & 2,04 & 0,27 & 1,98 \\
Feijão & 3,67 & 37,45 & 0,42 & 3,08 \\
Fumo & 0,12 & 1,22 & 1,40 & 10,26 \\
Hortifrutigranjeiros & 0,25 & 2,55 & 1,12 & 8,21 \\
Mandioca & 3,16 & 32,24 & 2,12 & 15,54 \\
Milho & 0,30 & 3,06 & 0,43 & 3,15 \\
Soja & 0,05 & 0,51 & 0,57 & 4,18 \\
Outras & 7,84 & 80,00 & 7,11 & 52,13 \\
Total & & & 13,64 & \\
Área média total da & 9,80 & & & \\
propriedade (ha) & & &
\end{tabular}

Fonte: Pesquisa de campo. 
nas propriedades de fumicultores e 0,42 hectare nas propriedades dos não fumicultores. Dessa forma, no caso dos fumicultores, a cultura do fumo ocupa $37,5 \%$ da área total da propriedade, o milho ocupa cerca de $32 \%$ da área total, enquanto que as demais culturas que apresentam alguma forma de comercialização ocupam pouco mais de $10 \%$ da área total da propriedade. O restante da área da propriedade destina-se a outras formas de ocupação, tais como reflorestamento, pastagens, açudes ou mata nativa.

No caso dos não fumicultores, as culturas com maior participação na área total da propriedade são a do milho (15,5\%), hortifrutigranjeiros $(10,2 \%)$ e mandioca $(8,2 \%)$, conforme demonstra a Tabela 6 .

A Tabela 7 a seguir apresenta o valor médio obtido por fumicultores e não fumicultores como resultado das atividades de produção agropecuária referentes ao período da safra 2007/2008.
A receita anual média da produção dos fumicultores equivale a $\mathrm{R} \$ 41.153,79$ em comparação com um valor de receita anual média dos não fumicultores de $\mathrm{R} \$ 30.483,95$. Tais valores representam a receita anual obtida pelos produtores com a comercialização da sua produção vegetal e animal decorrente das atividades agropecuárias desenvolvidas nas propriedades. Tais atividades contemplam tanto a produção agrícola quanto a de criação (pecuária, avicultura, suinocultura etc.).

No grupo fumicultores, no tocante exclusivamente à receita bruta obtida com a cultura do fumo, constatou-se uma receita anual de R\$ $39.615,98$ na safra $2007 / 2008$, o que representa a maior receita anual obtida no âmbito da pesquisa. Adicionalmente, verifica-se que o fumo representa $96,26 \%$ do total da receita anual obtida pelos fumicultores com as atividades agropecuárias, o que demonstra a forte especialização inerente a esse tipo de atividade. A produção de milho

Tabela 7. Receita bruta da produção agropecuária para fumicultores e não fumicultores, safra 2007/2008 (valores médios em R\$).

\begin{tabular}{|c|c|c|c|c|c|c|}
\hline \multirow{2}{*}{ Produção } & \multicolumn{3}{|c|}{ Fumicultor } & \multicolumn{3}{|c|}{ Não fumicultor } \\
\hline & $\mathbf{N}$ & Receita média & $\% \mathrm{~s} /$ receita total & $\mathbf{n}$ & Receita média & $\% \mathrm{~s} /$ receita total \\
\hline Arroz & 222 & 67,57 & 0,16 & 77 & 883,12 & 2,82 \\
\hline Batatinha & 222 & 3,60 & 0,01 & 74 & 73,58 & 0,24 \\
\hline Cebola & 221 & - & 0,00 & 72 & 220,14 & 0,70 \\
\hline Erva-Mate & 222 & 3,60 & 0,01 & 74 & 148,65 & 0,48 \\
\hline Feijão & 220 & 51,07 & 0,12 & 75 & 517,73 & 1,66 \\
\hline Fumo & 192 & $39.615,98$ & 96,26 & 77 & $3.937,66$ & 12,59 \\
\hline Hortifrutigranjeiros & 222 & 107,27 & 0,26 & 63 & $12.933,33$ & 41,35 \\
\hline Mandioca & 221 & 32,81 & 0,08 & 67 & $2.655,52$ & 8,49 \\
\hline Milho & 215 & 407,91 & 0,99 & 68 & $1.147,15$ & 3,67 \\
\hline Soja & 222 & 482,43 & 1,17 & 76 & 715,39 & 2,29 \\
\hline Outras & 221 & 100,45 & 0,24 & 71 & $3.098,24$ & 9,91 \\
\hline Receita bruta da produção vegetal & & $40.872,69$ & 99,32 & & $26.330,51$ & 84,19 \\
\hline Avicultura & 222 & 12,39 & 0,03 & 76 & 238,16 & 0,76 \\
\hline Bovinos de corte & 222 & 23,87 & 0,06 & 77 & 131,17 & 0,42 \\
\hline Bovinos de leite & 221 & 163,10 & 0,40 & 75 & $2.900,07$ & 9,27 \\
\hline Piscicultura & 222 & 59,19 & 0,14 & 76 & 754,93 & 2,41 \\
\hline Suínos & 222 & 19,14 & 0,05 & 75 & 398,00 & 1,27 \\
\hline Outros & 220 & 3,41 & 0,01 & 75 & 522,69 & 1,67 \\
\hline Receita bruta da produção animal & & 281,10 & 0,68 & & $4.945,02$ & 15,81 \\
\hline Receita bruta anual & & $41.153,79$ & 100,00 & & $31.275,53$ & 100,00 \\
\hline
\end{tabular}

Fonte: Pesquisa de campo. 
(cerca de $1 \%$ da receita bruta) aparece como segundo produto em termos de importância na composição de receitas dos fumicultores, enquanto que a produção de leite $(0,4 \%$ da receita bruta) representa o terceiro item de produção em termos de importância na geração de receita na propriedade. Tal evidência contradiz o argumento amplamente utilizado pelas organizações ligadas à indústria fumageira, de que os fumicultores na região do Vale do Rio Pardo (e de uma maneira geral) já contam com um elevado grau de diversificação na sua produção agrícola.

No caso dos não fumicultores, a maior receita média obtida com a produção agropecuária está associada à produção de hortifrutigranjeiros, que representou, na safra 2007/2008, uma receita bruta anual de $\mathrm{R} \$ 12.141,75$, ou o equivalente a cerca de $40 \%$ da receita bruta anual do grupo de 63 não fumicultores que responderam à questão. A produção de fumo aparece como o segundo item de produção mais importante nesse grupo na medida em que responde por $12,6 \%$ da receita bruta $(\mathrm{R} \$ 3.937,66)$. Em terceiro lugar, destaca-se a produção de leite, que responde por cerca de 10\% da receita bruta entre os não fumicultores.

Cabe ressaltar que a análise da estrutura de receitas dos dois grupos considerados neste estudo (fumicultores e não fumicultores), tal como é apresentada, demanda alguns esclarecimentos adicionais. No caso do grupo de fumicultores, considera-se que o valor médio da receita bruta apresentado na tabela consiste numa boa aproximação da estrutura de receita daqueles produtores que adotam o fumo como sua principal cultura. No caso dos não fumicultores, entretanto, verifica-se um menor grau de homogeneidade nas estruturas produtivas na medida em que esse grupo agrega produtores especializados em diferentes tipos de atividades agropecuárias (como horticultura, avicultura ou suinocultura, por exemplo). A inclusão desses produtores no grupo de não fumicultores, nesse caso, se deve ao fato de eles não terem a fumicultura como sua principal fonte de renda.

A fim de se contornar essa limitação, buscou-se analisar a estrutura de receita dos não fumicultores que têm na produção de hortifrutigranjeiros a sua principal atividade econômica. Tal escolha se justifica pelo fato de que esses produtores representam mais da metade da amostra total de não fumicultores (Tabela 8). É interessante observar, também, que a receita máxima obtida com a produção de hortifrutigranjeiros, equivalente a $\mathrm{R} \$ 200.000$, supera a receita máxima obtida com a produção de fumo ( $R \$ 180.000)$.

Assim, considerando-se a receita anual média destes 49 produtores que têm na hortifruticultura sua principal fonte de renda, observa-se uma receita bruta anual de $\mathrm{R} \$ 31.480,55$, superior, portanto, à receita bruta apresentada na tabela acima, que considera o valor total médio da comercialização de hortifrutigranjeiros em função do número total de não fumicultores (77).

Cabe ressaltar que a receita anual apresentada acima não representa o rendimento líquido obtido pelo produtor rural, mas, sim, o montante total obtido ao final de um ano pela sua produção agropecuária. Dessa forma, tais informações devem ser analisadas junto às respectivas estruturas de custos destes dois grupos de produtores a fim de fornecer uma noção mais clara sobre as eventuais diferenças em termos de rendimento médio para fumicultores e não

Tabela 8. Receitas operacionais para produtores de hortifrutigranjeiros, safra 2007/2008 (valores médios em R\$).

\begin{tabular}{lcccc}
\hline \multicolumn{1}{c}{ Tipo de receita } & $\mathbf{n}$ & Não produz hortifrutigranjeiro & & Produtor de hortifrutigranjeiro \\
\cline { 5 - 6 } \cline { 5 - 6 } & & Receita média & & Receita média \\
\hline $\begin{array}{l}\text { Receita anual obtida com a venda da } \\
\text { produção vegetal }\end{array}$ & 20 & 22.631 & & $27.240,33$ \\
$\begin{array}{l}\text { Receita anual obtida com a venda da } \\
\text { produção animal }\end{array}$ & 23 & $4.408,7$ & 51 & $5.308,47$ \\
Receita total & 22 & $25.182,73$ & 51 & $31.480,55$ \\
\hline
\end{tabular}

Fonte: Pesquisa de campo. 
fumicultores. Assim, o estudo buscou levantar informações sobre os custos de produção referentes à principal cultura de cada grupo (fumicultores e não fumicultores) no período da safra 2007/2008. Os resultados preliminares deste levantamento são apresentados na Tabela 9.

De acordo com os dados obtidos, o custo anual total de produção dos fumicultores equivale, em média, a $\mathrm{R} \$ 23.582,08$. Este montante inclui tanto os custos variáveis quanto os custos fixos de produção, conforme detalhado na tabela abaixo. No caso dos custos variáveis, consideram-se os gastos incorridos com mão de obra permanente e temporária, suprimentos agrícolas, operações com implementos, entre outras. Entretanto, tais custos desconsideram o custo estimado do uso de mão de obra familiar, tanto para fumicultores quanto para não fumicultores. Os custos fixos englobam, majoritariamente, os valores de depreciação, que servem de base para investimentos na reposição dos ativos fixos utilizados na produção agropecuária, além dos gastos com correção de solo.

No caso dos fumicultores, os custos variáveis de produção representam $86,7 \%$ dos custos totais de produção, sendo que os suprimentos agrícolas respondem por cerca de $40 \%$ dos custos variáveis. Para os demais produtores, o custo anual total de produção no mesmo período foi equivalente a $\mathrm{R} \$ 11.211,14$, sendo que, deste montante, $76,6 \%$ estiveram associados aos custos variáveis (R\$ 8.589,53) e 23,4\%, aos custos fixos.

Tabela 9. Custos operacionais de produção para fumicultores e não fumicultores, safra 2007/2008, valores médios em R\$.

\begin{tabular}{|c|c|c|c|c|c|c|}
\hline \multirow{2}{*}{ Custos operacionais } & \multicolumn{3}{|c|}{ Fumicultores } & \multicolumn{3}{|c|}{ Não fumicultores } \\
\hline & $\mathbf{n}$ & Valor médio & $\% \mathrm{~s} /$ custo total & $\mathbf{n}$ & Valor médio & $\% \mathrm{~s} /$ custo total \\
\hline \multicolumn{7}{|l|}{ 1. Custos Variáveis } \\
\hline Mão de obra permanente & 220 & $1.203,32$ & 5,10 & 77 & $1.195,84$ & 10,67 \\
\hline Mão de obra temporária & 214 & $2.182,81$ & 9,26 & 77 & 846,36 & 7,55 \\
\hline Operações com animais & 215 & 130,47 & 0,55 & 77 & 210,39 & 1,88 \\
\hline Operações com máquinas & 212 & 856,50 & 3,63 & 75 & $1.238,80$ & 11,05 \\
\hline Operações com benfeitorias & 215 & 499,91 & 2,12 & 77 & 654,03 & 5,83 \\
\hline Suprimentos agrícolas & 215 & $9.376,63$ & 39,76 & 74 & $2.531,22$ & 22,58 \\
\hline Lenha & 215 & $3.027,21$ & 12,84 & 77 & 358,18 & 3,19 \\
\hline Energia elétrica & 206 & 622,07 & 2,64 & 75 & 969,72 & 8,65 \\
\hline Seguro da produção & 203 & 955,88 & 4,05 & 72 & 115,97 & 1,03 \\
\hline Funrural & 89 & $1.067,07$ & 4,52 & 20 & 331,95 & 2,96 \\
\hline Despesas financeiras & 185 & 531,66 & 2,25 & 75 & 137,07 & 1,22 \\
\hline Subtotal & & $20.453,53$ & 86,73 & & $8.589,53$ & 76,62 \\
\hline \multicolumn{7}{|l|}{ 2. Custos Fixos } \\
\hline Correção do solo & 206 & 726,24 & 3,08 & 76 & 813,55 & 7,26 \\
\hline Depreciação de utensílios & 214 & 54,05 & 0,23 & 77 & 648,77 & 5,79 \\
\hline Depreciação de implementos & 215 & 341,79 & 1,45 & 77 & 234,87 & 2,09 \\
\hline Depreciação de animais e máquinas & 219 & $1.088,11$ & 4,61 & 77 & 534,81 & 4,77 \\
\hline Depreciação de benfeitorias & 219 & 918,36 & 3,89 & 77 & 389,61 & 3,48 \\
\hline Sub total & & $3.128,55$ & 13,27 & & $2.621,61$ & 23,38 \\
\hline Total $(1+2)$ & & $23.582,08$ & 100,00 & & $11.211,14$ & 100,00 \\
\hline \multicolumn{7}{|l|}{ Receita bruta anual } \\
\hline Receita líquida & & $17.571,71$ & & & $20.064,39$ & \\
\hline Participação dos custos na receita & & 57,3 & & & 35,8 & \\
\hline
\end{tabular}

Fonte: Pesquisa de campo. 
Verifica-se, portanto, que o grupo de produtores dedicados majoritariamente a outras culturas que não o fumo apresenta um custo total anual que é, em média, cerca de metade daquele incorrido pelos fumicultores na sua produção. Entretanto, conforme foi destacado anteriormente, na interpretação destes resultados preliminares deve-se considerar a existência de uma maior heterogeneidade nas estruturas de custos do grupo de não fumicultores, devido à maior diversidade em termos das atividades produtivas que constituem sua principal fonte de renda.

A partir dos dados disponíveis verifica-se que, por um lado, a cultura do fumo oferece uma receita anual que é cerca de três vezes maior do que a receita bruta anual obtida pelo grupo dos não fumicultores com a produção de hortifrutigranjeiros. Da mesma forma, a receita bruta anual dos fumicultores é, em média, cerca de $30 \%$ superior à obtida pelos não fumicultores. Por outro lado, os custos totais de produção dos fumicultores são equivalentes ao dobro do custo de produção dos não fumicultores. Assim, verifica-se que o resultado financeiro líquido obtido pelos não fumicultores da amostra (equivalente a $\mathrm{R} \$ 20.064,39)$ supera em $14 \%$ a receita líquida dos fumicultores ( $\mathrm{R} \$ 17.571,71)$.

De maneira geral, as evidências apresentadas acima contradizem grande parte das análises comparativas envolvendo fumo e demais culturas agrícolas geralmente veiculadas pela indústria fumageira e particularmente pela Associação dos Fumicultores do Brasil (Afubra). De acordo com esse tipo de análise, ainda que a rentabilidade deste tipo de atividade tenha caído nos últimos anos, o fumo continua sendo uma cultura altamente atrativa para essas famílias de pequenos agricultores, proporcionando uma renda líquida por unidade de terra mais elevada do que outros cultivos convencionais de alimentos, tais como milho ou feijão preto (AFUBRA, 2008).

Finalmente, destaca-se que o lucro bruto do fumo comparado ao de culturas alternativas constitui um ponto-chave de qualquer programa de substituição de cultivo destinado a apoiar pequenos produtores a trocar o plantio do fumo pelo de outras culturas. Neste aspecto, argumenta-se que uma análise mais ampla sobre o processo de geração de renda envolvendo pequenas propriedades rurais nos moldes do que foi apresentado acima permite uma comparação entre renda líquida advinda da cultura do fumo e de produtores que atuam com culturas alternativas como principal fonte de renda.

Cabe destacar, também, que dados divulgados pela Afubra demonstram que os custos estimados para produção de tabaco são cerca de cinco vezes maiores do que os custos associados à produção de milho e cerca de seis vezes acima dos custos com a produção de feijão. Tal diferença reflete, em particular, a quantidade de trabalho demandada para a produção de tabaco (149 dias/ pessoa/hectare) em comparação com as demais culturas (AFUBRA, 2008; VARGAS e BONATO, 2007). Adicionalmente, estudos anteriores sobre estratégias de diversificação da cultura do fumo na região do Vale do Rio Pardo baseados em estimativas das receitas de pequenos agricultores engajados em atividades de produção agroecológica demonstraram que tais atividades proporcionam alternativas viáveis ao cultivo do tabaco para os pequenos agricultores da região, em termos de rentabilidade, comercialização e financiamento da produção (VARGAS e CAMPOS, 2005; VARGAS e BONATO, 2007) ${ }^{12}$.

Uma questão adicional importante na análise sobre barreiras à substituição dos cultivos de tabaco no Sul do Brasil refere-se ao papel das políticas de financiamento governamentais (em

\footnotetext{
12 De acordo com os dados fornecidos pela própria Afubra, na safra 1999/2000, o fumo proporcionava um retorno de US\$ 360,91 a US\$ 454,57 por hectare. Uma propriedade produtora de fumo no Brasil possui, em média, 18,5 hectares, dos quais 2,6 são ocupados para o plantio do fumo. Assim, a receita líquida média do fumo, por família, foi estimada entre US\$ 938,37 e US\$ 1.181,88. Neste mesmo período, de acordo com estimativas do Centro de Apoio ao Pequeno Agricultor (Capa), referente às atividades de comercialização de produtos agroecológicos, os pequenos agricultores associados à Ecovale apresentavam renda média anual de US\$ 1.560 (esta renda varia entre o mínimo de US\$ 312 e o máximo de US\$4.684).
} 
termos locais, estaduais e federais), que afetam a decisão de produtores rurais no Sul do Brasil no tocante à escolha do fumo ou de outras culturas como atividade principal. Como salientado anteriormente, o cultivo do fumo no Brasil está concentrado em determinadas regiões do Sul do País que dependem muito mais intensamente dessa cultura do que o País como um todo. Dessa forma, verifica-se que o peso do tabaco na economia regional geralmente impede a implementação de políticas locais voltadas a fomentar a substituição deste cultivo.

A Figura 1 mostra os resultados da pesquisa no tocante ao perfil de acesso a políticas públicas por parte de fumicultores e de não fumicultores. Com exceção dos benefícios de aposentadoria, que são utilizados por $48 \%$ dos não fumicultores e por apenas $25 \%$ dos fumicultores, verifica-se o maior acesso relativo dos fumicultores à maior parte das políticas públicas destinadas ao desenvolvimento da agricultura familiar na região. Em particular, destaca-se o amplo acesso dos fumicultores aos recursos do Pronaf (custeio e investimento), que constitui um dos principais fundos governamentais de apoio à agricultura familiar em âmbito nacional. Dessa forma, verifica-se que, entre os fumicultores, $62 \%$ tiveram acesso aos recursos do Pronaf-custeio e 54,4\% tiveram acesso ao Pronaf-investimento. Por outro lado, entre os não fumicultores, apenas 38,3\% tiveram acesso aos recursos do Pronaf-custeio entre os anos de 2006 e 2007, enquanto que $41,7 \%$ acessaram recursos do Pronaf-investimento. Da mesma forma, o percentual de fumicultores que tiveram acesso ao seguro Proagro Mais $(23,4 \%)$ supera o percentual de não fumicultores que tiveram acesso a esse tipo de política $(16,7 \%)$.

Finalmente, além de proceder com a análise da estrutura de receitas e custos dos produtores de fumo e de outras culturas, o estudo buscou também a opinião dos produtores sobre as principais vantagens e/ou desvantagens associadas à cultura do fumo.

A Figura 2 mostra as principais razões que foram apontadas pelos fumicultores para produzir tabaco. A rentabilidade mais elevada da cultura do fumo em relação às demais foi o motivo mais citado pelos fumicultores, obtendo $94,5 \%$ das respostas afirmativas. Em seguida, foi destacada a demanda mais reduzida de área para

Figura 1. Acesso a políticas públicas.

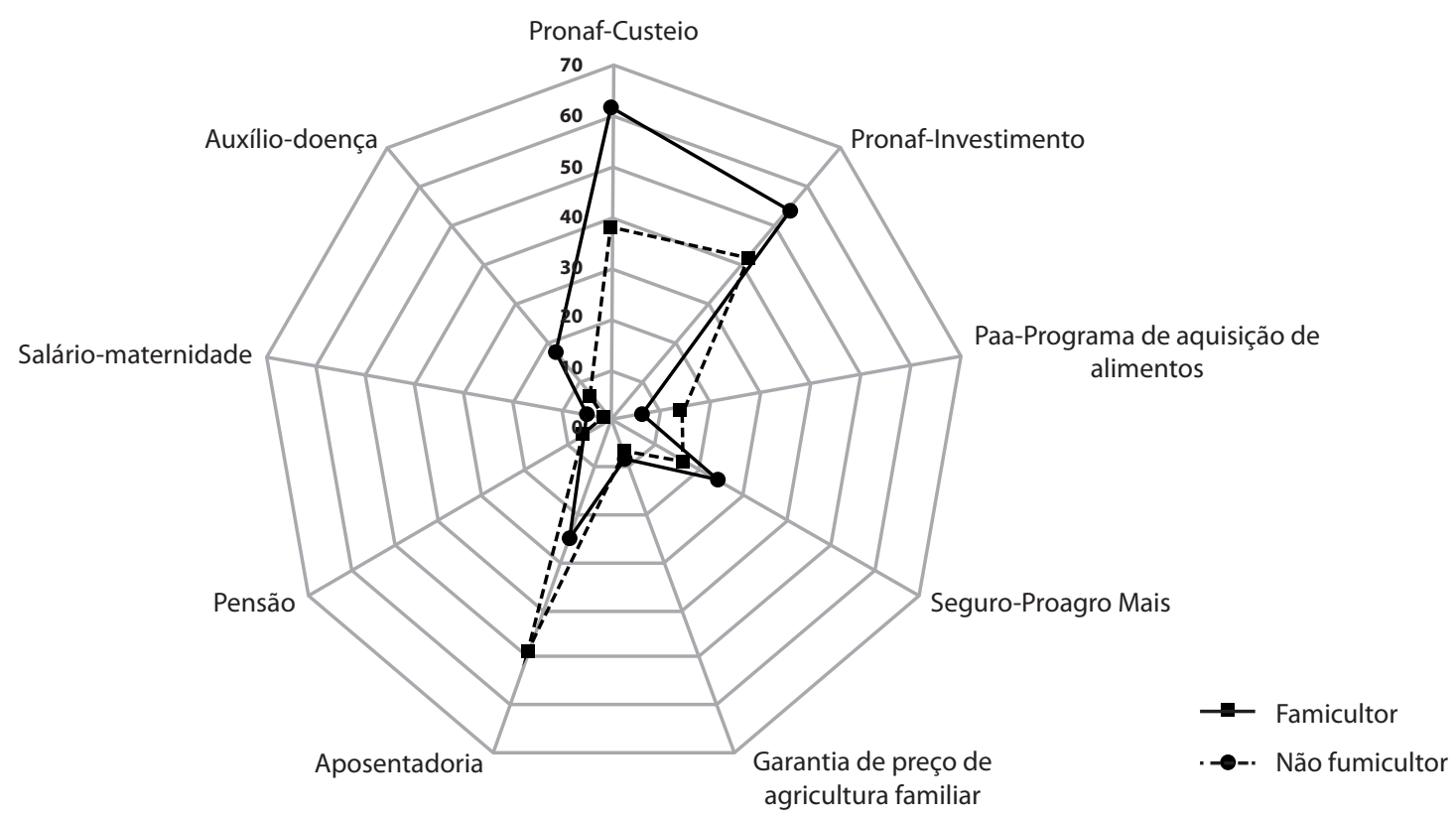

Fonte: Pesquisa de campo. 
Figura 2. Vantagens da cultura do fumo em relação às demais.

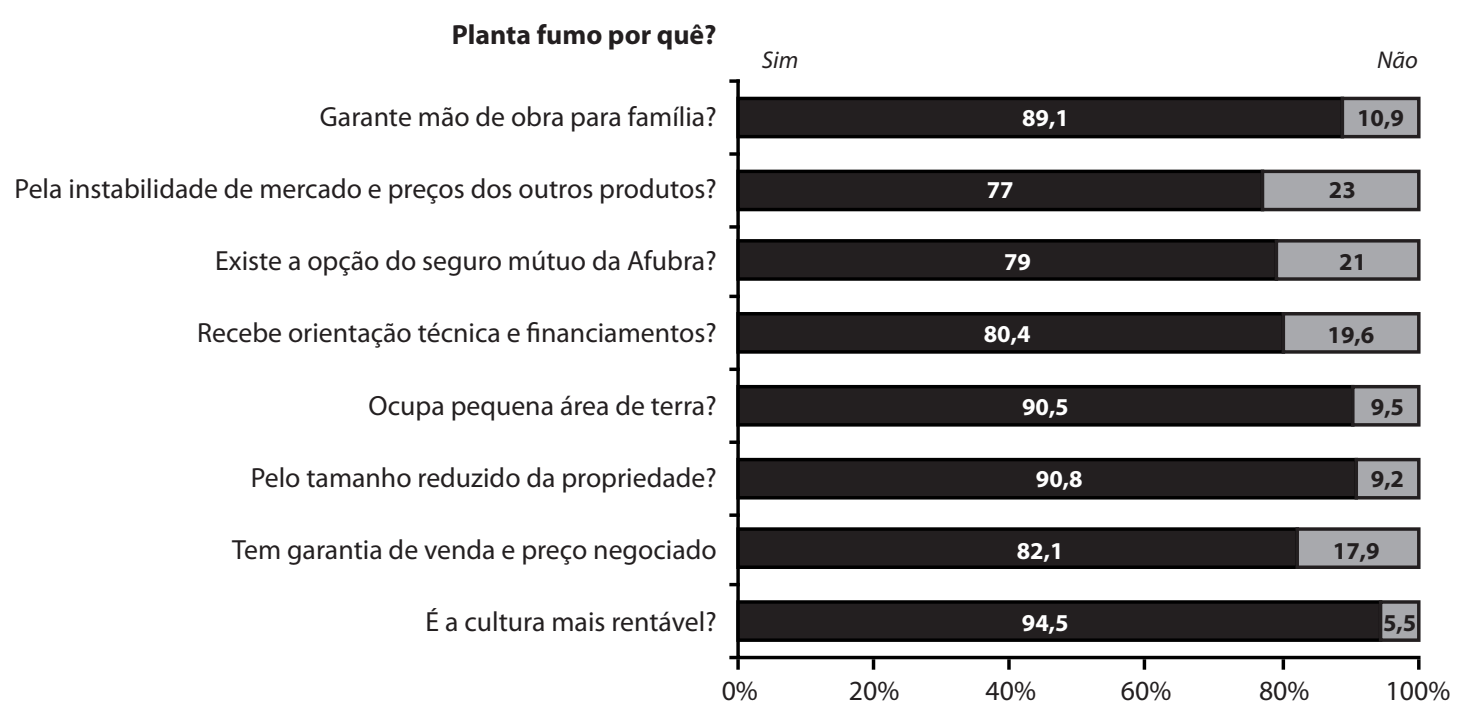

Fonte: Pesquisa de campo.

plantio na propriedade $(90,5 \%)$ e a possibilidade de ocupação da mão de obra familiar $(89,1 \%)$. Entre os fatores considerados como motivos menos importantes pelos fumicultores para a escolha do fumo como principal cultura estão a instabilidade de mercado e preços para os demais produtos agrícolas e a existência da opção de seguro mútuo da AFfubra.

\section{Conclusões}

Este artigo buscou apresentar um panorama geral sobre os principais aspectos socioeconômicos associados à cultura do fumo na regiãoSul do Brasil e avaliar a viabilidade de outras culturas agrícolas em relação à produção de fumo na região do Vale do Rio Pardo a partir de dados provenientes de uma pesquisa de campo envolvendo uma amostra segmentada entre grupos de produtores vinculados majoritariamente à produção de fumo ou de outras atividades de produção agrícola ou animal.

Conforme foi discutido na parte inicial deste estudo, no Brasil, a expansão da produção de fumo na região Sul, particularmente durante a década de 90, ampliou o poder das grandes empresas fumageiras sobre as atividades de cultivo do fumo e criou importantes obstáculos em termos de rotas de desenvolvimento regional em muitas localidades. Apesar destes obstáculos, a análise do conjunto parcial de informações oriundas da pesquisa de campo evidencia, a partir de uma análise mais ampla sobre o processo de geração de renda em pequenas propriedades rurais, que a renda líquida advinda de culturas alternativas ao fumo pode ser superior àquela obtida por fumicultores.

Em vista do exposto, é possível destacar alguns pontos centrais no tocante à implementação de programas de diversificação em áreas de cultivo de fumo. Tais considerações podem ser resumidas como segue:

Em primeiro lugar, considera-se que qualquer iniciativa específica de diversificação deve estar inserida em programas amplos de desenvolvimento rural, particularmente nas regiões/municípios que têm alta dependência em relação ao fumo. O estudo de casos brasileiros evidencia que os esforços para estimular a substituição de cultura têm sido relacionados à identificação de novos canais de distribuição e a oportunidades para agregar valor às culturas 
alternativas de alimentos. Além do potencial de geração de renda, é importante também levar em conta a segurança e a estabilidade para a produção e a comercialização, as condições de reprodução da família, as condições de saúde e bem-estar da família, entre outras variáveis.

Em segundo lugar, a análise sugere também que, em regiões dominadas pelo cultivo do fumo, os governos locais/estaduais têm interesse bastante limitado em liderar programas de substituição deste cultivo. Parcerias com autoridades governamentais locais constituem fatores críticos para disseminar e consolidar esforços mais amplos de diversificação entre os agricultores.

Finalmente, é importante enfatizar que qualquer estratégia de substituição ou diversificação do cultivo do tabaco deve estar adaptada às especificidades das estruturas regionais/locais de produção. $\mathrm{O}$ acesso a mecanismos e políticas que promovam a diversificação deve estar conectado a dinâmicas voltadas à reestruturação dos processos de desenvolvimento da região em que a produção de fumo está inserida.

Diante disso, os programas de diversificação nas áreas de cultivo de fumo devem considerar diversos fatores, articuladamente: capacidade de geração de renda, segurança e estabilidade na produção e comercialização, condições de reprodução familiar, bem-estar e saúde da família, entre outros. Além disso, as propostas devem levar em consideração não somente a unidade familiar, individualmente, mas sua inserção na comunidade e no território. $\mathrm{O}$ acesso a mecanismos e políticas que potencializem a diversificação precisa estar vinculado a dinâmicas que repensem os processos de desenvolvimento dos territórios onde a produção de tabaco está inserida.

\section{Referências bibliográficas}

AID, C. (2002). "Hooked on Tobacco: Report by Christian Aid/SESER on British American Tobacco Subsidiary., Souza Cruz, Christian Aid, London.

ASSOCIAÇÃO DE FUMICULTORES BRASILEIROS (AFUBRA). Disponível em: <www.afubra.com.br>. Acessado em: 20 mar. 2008.
ANUÁRIO BRASILEIRO DO FUMO. Santa Cruz do Sul: Gazeta Grupo de Comunicações, vários anos.

BONATO, A. (2006) "A Fumicultura no Brasil e a Convenção-Quadro Para Controle do Tabaco." Nota Técnica apresentada na $1^{\text {a }}$ Reunião do Grupo de Estudos Ad Hoc sobre Alternativas Agrícolas à Produção de Fumo. Brasília, mimeo

BUCK, D.; GODFREY, C.; RAW, M; SUTTON, M. (1995). "Tobacco and Jobs."York, U.K.: Society for the Study of Addiction and the Centre for Health Economics, University of York.

CARNEY, D. (1998). Implementing the sustainable rural livelihoods approach. Trabalho apresentado no DfID Natural Resource Advisers' Conference. London: Department for International Development.

CHAMBERS, R. (1983). Rural Development: putting the last first. London, Longman.

CHAMBERS, R. E CONWAY, G. (1992) Sustainable rural livelihoods: Practical concepts for the 21st century. IDS Discussion Paper 296. Brighton: IDS.

DESER (2003). "A Cadeia Produtiva do Fumo". Revista Contexto Rural. Ano III, nº4, dez. 2003.

FAO (2003). "Issues in the Global Tobacco Economy: Selected Case Studies". FAO Commodity Studies No. 2, Food and Agriculture Organization, Commodities and Trade Division, Raw Materials, Tropical and Horticultural Products Service, Rome.

FROEHLICH, J. M.; DULLIUS, P. R.; PIETRZACKA, R. (2005) A Multifuncionalidade do Espaço Rural na Região Central do Rio Grande Do Sul - Dados Gerais. Trabalho apresentado no XLIII Congresso da Sociedade Brasileira de Economia e Sociologia Rural 2005.

INSTITUTO BRASILEIRO DE GEOGRAFIA ESTATÍSTICA - IBGE. Produção Agrícola Municipal (PAM) 2005. Disponível em: <www.ibge.gov.br>. Acessado em: 20 mar. 2008.

INSTITUTO NACIONAL DO CÂNCER - INCA. "Convenção-Quadro para o Controle do Tabaco - Documento Síntese." Secretaria Executiva da Comissão Nacional para Implementação da Convenção-Quadro para o Controle do Tabaco e de seus Protocolos (CONICQ).

JACOBS, R; GALE H. F;; CAPEHART, T. C.; ZHANG, P.; JHA, P. (2000). "The Supply-side Effects of Tobacco Control Policies" in Tobacco Control in Developing Countries, Prabhat Jha and Frank Chaloupka editors, pp 311-341, Oxford University Press, Oxford.

OLALDE, A R E PORTUGAL, C A. Agricultura Familiar, Reforma Agrária e sua inserção no enfoque territorial no 
Brasil. Trabalho apresentado no XLII Congresso da Sociedade Brasileira de Economia e Sociologia Rural , Cuiabá-MT, 2004

SCHNEIDER, S. Agricultura familiar e pluriatividade. Porto Alegre: Editora da Universidade, 1999.

SCOONES, I (1998). Sustainable rural livelihoods: a framework for analysis. IDS working paper, 72 . Brighton: IDS

SCOONES, I (2009) . Livelihoods perspectives and rural development. Journal of Peasant Studies, 36: 1, 171-196

VAN DER MERWE, R. (1998). "Employment and Output Effects for Bangladesh Following a Decline in Tobacco Consumption." Population, Health and Nutrition Department. The World Bank.

VARGAS, M. A.; CAMPOS, R.R. (2005). "Crop Substitution and Diversification Strategies: Empirical Evidence from Selected Brazilian Municipalities". HNP Discussion Paper, Economics of Tobacco Control Paper, No. 28, The World Bank, Washington DC.
VARGAS, M. A., (2004). "From Seed to Smoke: The relationship between global governance and local development strategies in the Tobacco Value Chain." Report prepared for the project "Transition from Tobacco to Sustainable Livelihoods". Rockefeller Foundation, New York, mimeo.

VEIGA et al. O Brasil rural precisa de uma estratégia de desenvolvimento. In: Série Textos para discussão, No1. Brasília: MDA/CNDRS/NEAD. CD ROOM - NEA, 2001.

WARNER, K. E.; FULTON, G. A.; NICOLAS, P.; GRIMES, D. R. (1996). "Employment Implications of Declining Tobacco Product Sales for the Regional Economies of the United States." Journal of the American Medical Association 275(16):1241-6.

WORLD BANK. (1999). "Curbing the Epidemic: Governments and the Economics of Tobacco Control." Washington: World Bank.

WORLD HEALTH ORGANIZATION (2004). "Building blocks for tobacco control: a handbook. Tobacco Free Initiative." WHO, Geneva. 